\title{
Calcification of the internal elastic lamina of coronary arteries
}

\author{
Robert G Micheletti ${ }^{1}$, Gregory A Fishbein ${ }^{2}$, Judith S Currier ${ }^{1}$, Elyse J Singer ${ }^{3}$ and \\ Michael C Fishbein ${ }^{2}$ \\ ${ }^{1}$ Division of Infectious Diseases, Department of Medicine, University of California at Los Angeles, \\ Los Angeles, CA, USA; ${ }^{2}$ Department of Pathology and Laboratory Medicine, University of California \\ at Los Angeles, Los Angeles, CA, USA and ${ }^{3}$ Department of Neurology, University of California at Los Angeles, \\ Los Angeles, CA, USA
}

\begin{abstract}
Two well-recognized patterns of calcification occur in large- and medium-sized arteries, intimal calcification associated with atherosclerosis and medial calcification described by Mönckeberg. Calcification limited to the internal elastic lamina is a third pattern of calcification not previously reported in coronary arteries. Here we describe 19 cases of coronary artery internal elastic lamina calcification. We serially sectioned and examined the coronary arteries of 66 patients with advanced AIDS and 27 HIV-controls with other chronic illnesses. We observed calcification of the internal elastic lamina in $10 \mathrm{HIV}+$ patients and 9 controls. HIV - patients with internal elastic lamina calcification were significantly older than HIV - patients without it $(P=0.008)$ and HIV + patients with it $(P=\mathbf{0 . 0 0 6})$. Occasionally, calcification encroached on adjacent intimal or medial tissue with mild fibrosis. There was frequent disruption of the internal elastic lamina but no evidence of inflammation. Calcification was the dominant histologic feature in all cases. Von Kossa, Alizarin red, and trichrome/elastic stains confirmed these findings. Patients with internal elastic lamina calcification often had extensive medical histories but did not suffer from chronic renal failure or other conditions known to cause calcium dysregulation. We describe coronary internal elastic lamina calcification in HIV + patients and older HIV- adults. The clinical significance of this finding is unknown. It could lead to arterial stiffening and increased pulse pressure and could be mistaken for intimal calcification on coronary imaging. Internal elastic lamina calcification may result from premature aging due to HIV disease and chronic illness or from metabolic disorders in HIV + patients. Modern Pathology (2008) 21, 1019-1028; doi:10.1038/modpathol.2008.89; published online 6 June 2008
\end{abstract}

Keywords: calcium; internal elastic lamina; AIDS; aging

There appears to be a consensus of opinion that there are two patterns of calcification that occur in large- and medium-sized arteries. ${ }^{1-3}$ Intimal calcification is found in large arteries, including the coronaries, and is associated with atherosclerotic plaques. Medial calcification, first described by Mönckeberg, ${ }^{4}$ is independent of atherosclerosis and is seen primarily in the media of muscular arteries of the extremities and only rarely in the visceral or coronary arteries. There is, however, a third pattern of calcification that appears to be distinct from both intimal and medial calcification and which has received far less attention-that is, calcification limited to the internal elastic lamina.

Correspondence: RG Micheletti, BA, University of California at Los Angeles, UCLA CARE Center, 9911 W Pico Boulevard, Ste 980, Los Angeles, CA 90035, USA.

E-mail: mrobert@mednet.ucla.edu or rgm7@duke.edu

Received 12 June 2007; revised 29 October 2007; accepted 31 October 2007; published online 6 June 2008
Calcification of the internal elastic lamina has been described in association with other pathologic findings in Buerger's disease, idiopathic infantile arterial calcification, diffuse arterial calcified elastopathy, and pseudoxanthoma elasticum. Internal elastic lamina calcification has also been reported in orbital and temporal arteries. The arterial changes associated with Buerger's disease are dramatic and distinct, characterized by total luminal obliteration and marked undulation, multiplication, and delicate linear calcification of the internal elastic lamina in small- and medium-sized vessels of the extremities. These changes in the internal elastic lamina are overshadowed by inflammation and thrombosis. ${ }^{5}$ Idiopathic infantile arterial calcification, a rare condition lethal in infancy, is associated with marked intimal proliferation and luminal occlusion as well as calcium deposition in the internal elastic lamina of medium and large muscular arteries, including the coronaries. ${ }^{6,7}$ Diffuse arterial calcified elastopathy, a condition leading to renovascular 
hypertension in children, is associated with calcification of the media, internal elastic lamina, and external elastic lamina as well as medial sclerosis and intimal fibrosis of the renal and other muscular arteries. ${ }^{8}$ Pseudoxanthoma elasticum, a rare condition associated with characteristic skin lesions, is associated with degeneration of elastic tissue in medium-sized arteries and focal calcification of the internal elastic lamina. ${ }^{9}$ In the orbital and temporal arteries, internal elastic lamina calcification has also been thought to be related to vascular degeneration and arteritis. ${ }^{10-12}$

Here we describe a new finding-calcification limited to the internal elastic lamina of coronary arteries of adult patients not associated with the known disorders discussed above and to our knowledge not previously reported elsewhere.

\section{Materials and methods}

This study is part of our ongoing research into the nature of coronary atherosclerosis in HIV-positive patients. For this research, we dissected and examined the hearts of 93 total patients. Seventyeight of these were enrolled in the National Neurological AIDS Bank, a tissue repository of patients dying of advanced AIDS and other terminal illnesses. Another 15 patients were randomly selected, routine hospital autopsy cases. Sixty-six of these 93 patients were 29- to 54-year-old and HIVpositive. The remaining 27 constituted a control group of HIV-negative patients, aged 26-78 years. Because our goal was to describe coronary atherosclerosis in these populations, we sampled the coronary arteries extensively, sectioning the entire left main, the first $2 \mathrm{~cm}$ of the left anterior descending, the first $2 \mathrm{~cm}$ of the left circumflex, and the first $3 \mathrm{~cm}$ of the right coronary artery at $2-3 \mathrm{~mm}$ increments. Approximately 24 coronary artery segments were examined per patient. All of these segments were processed routinely by two different laboratories and embedded in paraffin. Each block was cut into histologic sections, stained with hematoxylin and eosin (H\&E), and graded by three of the authors for the composition and severity of atherosclerotic plaques. Among other measures, coronary artery stenosis was estimated by visual inspection as the percent luminal narrowing due to atherosclerotic plaque. In 19 of the 93 patients, internal elastic lamina calcification of the coronary arteries was an unexpected finding.

In addition, we reviewed the general autopsy slides of 17 of the 19 patients with coronary artery internal elastic lamina calcification, looking for evidence of internal elastic lamina or medial calcification in systemic arteries. While the tissues sampled were extensive and the same in all patients according to the National Neurological AIDS Bank protocol, the aorta and carotid artery were the only arteries routinely sampled. Thus, the number and size of arteries visible in systemic tissue sections were not the same from patient to patient.
We also noted any general tissue pathology, paying special attention to histologic evidence of renal dysfunction, which has been linked to calcium dysregulation, marked calcification in atherosclerosis, Mönckeberg's medial sclerosis, and calciphylaxis. ${ }^{2,13,14}$ We performed von Kossa, Alizarin red, and trichrome/elastic staining on selected coronary and systemic tissue sections.

Finally, in addition to our histologic studies, we reviewed the clinical information of all 93 patients, including medical histories, medications, serum creatinine, and calcium levels where available. Student's $t$-test was used to evaluate differences in patient age and atherosclerotic burden.

This study received a waiver from the institutional review board. The authors had full access to the data, and take responsibility for its integrity. All authors have read and agree to the manuscript as written.

\section{Results}

The HIV-positive patients studied constituted a young to middle-aged group with an average age of 43 years. All were under 55 years of age. The HIVnegative control group included patients older than 55 years with an average age of $48 \quad(P=0.06)$. Overall, we identified calcification of the internal elastic lamina in 19 patients. Ten were HIV-positive and nine were HIV-negative controls. The demographic and medical characteristics of each patient are listed in Table 1. A comparison of patients with and without internal elastic lamina calcification can be seen in Table 2. Patients with calcification were significantly older than those without it $(P=0.004)$, and a greater percentage were HIV-negative $(P=0.06)$. There was no appreciable difference in the area of luminal stenosis due to atherosclerosis between these two groups, and creatinine, BUN, and calcium levels were essentially the same.

Because the HIV-positive patients in the study group were younger than the HIV-negative controls, we analyzed these two populations separately. Fifteen percent (10/66) of the young to middle-aged HIV-positive group had calcification of the internal elastic lamina. These patients ranged in age from 36 to 51 with an average age of 41 . Thirty-three percent (9/27) of the older HIV-negative group had calcification of the internal elastic lamina. They ranged in age from 27 to 78, with an average age of 58. Among HIV-negative patients, those with calcification were significantly older $(P=0.008)$ than those without it. HIV-negative patients with calcification were also significantly older than HIV-positive patients with it $(P=0.006)$. There was no age difference between HIV-positive patients with and without internal elastic lamina calcification. There was no significant race or sex difference between those with and without calcification of the internal elastic lamina.

Nearly all of the patients studied were suffering from chronic illnesses at the time of death, such as 
Table 1 Demographic and medical characteristics of affected patients

\begin{tabular}{|c|c|c|c|c|c|c|}
\hline Age & Sex & $\begin{array}{l}\text { HIV } \\
\text { status }\end{array}$ & Medical history ${ }^{\mathrm{a}}$ & Long-term medications & $A R F^{a}$ & $C R F^{\mathrm{a}}$ \\
\hline 51 & $\mathrm{M}$ & $\mathrm{HIV}+$ & $\begin{array}{l}\text { AIDS, diffuse B-cell lymphoma, } \\
\text { PCP, TB, hypogonadism, cryptococcal } \\
\text { meningitis, Guillain-Barre, smoking }\end{array}$ & $\begin{array}{l}\text { Extensive antiretroviral exposure, } \\
\text { bupropion, epoetin alfa, megestrol } \\
\text { acetate, trimethoprim-sulfamethoxazole, } \\
\text { azithromycin, vitamin B, vitamin E, } \\
\text { testosterone, pregabalin }\end{array}$ & + & - \\
\hline 44 & $\mathrm{~F}$ & $\mathrm{HIV+}$ & $\begin{array}{l}\text { AIDS, vasculitis, HBV, PCP, ITP, } \\
\text { neuropathy, cocaine use, shingles }\end{array}$ & $\begin{array}{l}\text { Extensive antiretroviral exposure, } \\
\text { decadorabolin, paroxetine, valacyclovir, } \\
\text { testosterone, epoetin alfa }\end{array}$ & ? & - \\
\hline 44 & $\mathrm{M}$ & $\mathrm{HIV}+$ & $\begin{array}{l}\text { AIDS, HCV, HBV, hepatic encephalopathy, } \\
\text { PCP, anemia, seizure disorder, cocaine } \\
\text { use, schizophrenia }\end{array}$ & $\begin{array}{l}\text { Extensive antiretroviral exposure } \\
\text { Other: dapsone, azithromycin }\end{array}$ & - & - \\
\hline 42 & $\mathrm{M}$ & $\mathrm{HIV+}$ & $\begin{array}{l}\text { AIDS, pneumonia, wasting, HCV, } \\
\text { cryoglobulinemia, depression, HTN }\end{array}$ & $\begin{array}{l}\text { Extensive antiretroviral exposure, } \\
\text { thiamine, folate, hydrocortisone, vitamin } \mathrm{K} \text {, } \\
\text { aluminum hydroxide }\end{array}$ & + & - \\
\hline 36 & $\mathrm{M}$ & $\mathrm{HIV}+$ & $\begin{array}{l}\text { AIDS, CNS lymphoma, PCP, KS, } \\
\text { anemia, wasting, dementia, smoking, } \\
\text { cocaine use, HSV, neutropenia }\end{array}$ & $\begin{array}{l}\text { Extensive antiretroviral exposure, } \\
\text { trimethoprim-sulfamethoxazole }\end{array}$ & - & - \\
\hline 36 & $\mathrm{~F}$ & $\mathrm{HIV+}$ & $\begin{array}{l}\text { AIDS, CMV retinitis/enteritis, MAC, } \\
\text { pancytopenia, HCV, PCP, depression, } \\
\text { dementia, seizure disorder, HTN, } \\
\text { cocaine use }\end{array}$ & $\begin{array}{l}\text { Extensive antiretroviral exposure, } \\
\text { foscarnet, trimethoprim-sulfamethoxazole, } \\
\text { azithromycin, filgrastim, methadone, } \\
\text { epoetin alfa, citalopram, phenytoin, } \\
\text { mirtazapine }\end{array}$ & - & - \\
\hline 46 & $\mathrm{M}$ & $\mathrm{HIV+}$ & $\begin{array}{l}\text { AIDS, Stevens-Johnson syndrome, } \\
\text { HCV, HBV }\end{array}$ & $\begin{array}{l}\text { Unknown antiretroviral exposure, } \\
\text { temazepam }\end{array}$ & - & - \\
\hline 39 & $\mathrm{M}$ & $\mathrm{HIV+}$ & $\begin{array}{l}\text { AIDS, MAC, Parvovirus B19 } \\
\text { pancytopenia, wasting }\end{array}$ & $\begin{array}{l}\text { Extensive antiretroviral exposure, } \\
\text { lansoprazole, amitriptyline, trimethoprim- } \\
\text { sulfamethoxazole, acyclovir, azithromycin, } \\
\text { paroxetine, tegretol, filgrastim, nandralone, } \\
\text { delatestryl }\end{array}$ & $?$ & - \\
\hline 37 & $\mathrm{M}$ & $\mathrm{HIV+}$ & AIDS, HBV, syphilis, wasting & $\begin{array}{l}\text { No antiretroviral exposure, atovaquone, } \\
\text { azithromycin }\end{array}$ & - & - \\
\hline 37 & $\mathrm{M}$ & $\mathrm{HIV}+$ & AIDS, PML & $\begin{array}{l}\text { Extensive antiretroviral exposure, filgrastim, } \\
\text { atovaquone, azithromycin, venlafaxine, } \\
\text { pantoprazole, magnesium }\end{array}$ & - & - \\
\hline 51 & $\mathrm{~F}$ & $\mathrm{HIV}-$ & $\begin{array}{l}\text { Paraplegia due to HTLV-1 myelopathy, } \\
\text { osteomyelitis of the coccyx }\end{array}$ & $\begin{array}{l}\text { Citalopram, gabapentin, vitamin C, } \\
\text { epoetin alfa, multivitamin, hydrocortisone }\end{array}$ & + & - \\
\hline 63 & $\mathrm{~F}$ & HIV- & $\begin{array}{l}\text { ALS, CAD s/p stent, CHF, } \\
\text { hypothyroidism, } \\
\text { asthma, migraines, s/p hip } \\
\text { replacement }\end{array}$ & Unknown & + & - \\
\hline 61 & $\mathrm{~F}$ & HIV- & $\begin{array}{l}\text { ALS, CAD s/p MI, smoker, HTN, } \\
\text { hyperlipidemia, depression }\end{array}$ & $\begin{array}{l}\text { Riluzole, premarin, amitriptyline, } \\
\text { sertraline }\end{array}$ & - & - \\
\hline 64 & $\mathrm{~F}$ & HIV- & ALS & Riluzole & - & - \\
\hline 69 & $\mathrm{~F}$ & HIV- & $\begin{array}{l}\text { ALS, diabetes mellitus, osteoarthritis, } \\
\text { hyperlipidemia, depression, sick sinus } \\
\text { syndrome }\end{array}$ & Oral hypoglycemics, riluzole & - & - \\
\hline 78 & $\mathrm{M}$ & HIV- & $\begin{array}{l}\text { Metastatic prostate cancer, } \\
\text { myelogenous leukemia, CAD, smoker }\end{array}$ & Unknown & - & - \\
\hline 73 & $\mathrm{~F}$ & HIV- & ALS & Unknown & ? & ? \\
\hline 40 & $\mathrm{M}$ & $\mathrm{HIV}-$ & Unknown cause of death, cocaine use & Unknown & $?$ & $?$ \\
\hline 27 & $\mathrm{M}$ & HIV- & $\begin{array}{l}\text { Unknown cause of death, no known } \\
\text { past medical history }\end{array}$ & Unknown & - & - \\
\hline
\end{tabular}

${ }^{\mathrm{a}}$ Medical history: AIDS, acquired immunodeficiency syndrome; ALS, amyotrophic lateral sclerosis; ARF, acute renal failure; CAD, coronary artery disease; CHF, congestive heart failure; CMV, cytomegalovirus; CRF, chronic renal failure; HBV, hepatitis B; HCV, hepatitis C; HTLV-1, human T-cell lymphotropic virus-1; HTN, hypertension; HSV, herpes simplex virus; ITP, idiopathic thrombocytopenic purpura; KS, Kaposi's sarcoma; MAC, Mycobacterium avium complex; MI, myocardial infarction; PCP, Pneumocystis carinii pneumonia; PML, progressive multifocal leukoencephalopathy; s/p, status post.

${ }^{\mathrm{b}}$ Extensive antiretroviral exposure includes treatment with drugs from the three major antiretroviral classes over several years: nucleoside reverse transcriptase inhibitors, non-nucleoside reverse transcriptase inhibitors, and protease inhibitors.

AIDS-related opportunistic infections, amyotrophic lateral sclerosis, or metastatic cancer (Table 1). It is notable that several of the HIV patients in this study were hepatitis B co-infected. Among the HIV-positive patients, there was a trend toward lower CD4 counts for those with internal elastic lamina calcification $(P=0.07)$. One patient suffered from diabetes mellitus, but none of the other patients with calcification of the internal elastic lamina was known to have chronic renal insufficiency, hyperparathyroidism, or any other condition causing long-term calcium dysregulation. 
Table 2 Patients with and without internal elastic lamina calcification

\begin{tabular}{|c|c|c|c|}
\hline & Calcification $(\mathrm{n}=19)$ & No calcification $(\mathrm{n}=75)$ & $\mathrm{P}$-value \\
\hline Age (years) & 50.6 & 43.1 & 0.004 \\
\hline Percent HIV+ & 52.6 & 74.7 & 0.06 \\
\hline Area luminal stenosis & 28.5 & 34.2 & 0.30 \\
\hline CD4 count (HIV+) & $42(n=10)$ & $144(n=56)$ & 0.07 \\
\hline Creatinine & $0.9(n=7)$ & $0.9(n=44)$ & 0.63 \\
\hline BUN & $17(n=7)$ & $15(n=43)$ & 0.52 \\
\hline Calcium & $8.8(n=5)$ & $8.4(n=37)$ & 0.58 \\
\hline
\end{tabular}

Four patients had acute renal failure at the end of life, either by history or elevated serum creatinine level. All available calcium levels were normal. Patient medication lists tended to be long. HIVpositive patients had extensive exposure to antiretroviral therapy from all three major drug classes (protease inhibitors, nucleoside reverse transcriptase inhibitors, and non-nucleoside reverse transcriptase inhibitors). Other long-term medications included vitamin supplements, antidepressants, blood cell growth factors, and steroids as shown in Table 1. Short-term medications at the end of life included numerous antibiotics, analgesics, and other common medications that are not listed.

\section{Coronary Histology}

In each of these 19 patients, we observed a striking calcification of the internal elastic lamina (see Figures 1-4). Typically, the lamina was unusually prominent throughout, bearing a bright eosinophilic color on H\&E-stained sections (Figure 4a and e). Further inspection revealed areas of blue-staining calcification limited, usually exclusively, to the internal elastic lamina. In its mildest form, this calcification had the appearance of beads on a string against the background of the prominent internal elastic lamina (Figure 4e). When the calcification was more extensive, the beads coalesced to form linear calcium deposits along the internal elastic lamina, sometimes extending for some distance around the circumference of the vessel (Figures 1 and 3). Although the extent of calcification varied, the great majority of affected sections had involvement of less than $25 \%$ of the total length of the internal elastic lamina. The largest of these calcium deposits not only extended linearly along the internal elastic lamina but also expanded on either side of it, encroaching on the adjacent intima and media with equal frequency but always staying centered on the internal elastic lamina. When this occurred, we noted mild fibrosis of the intimal or medial tissue surrounding the calcification (Figure $4 \mathrm{~d}$ ).

We did not find inflammatory cells or other evidence of inflammation in any of the sections. There was no abnormal intimal or medial hyperplasia except in cases of concomitant atherosclerosis. We frequently, but not always, noted gaps in the lamina and reduplication of the internal elastic lamina associated with areas of calcification (Figure 1d), suggesting a pattern of damage and disruption of the internal elastic lamina that was particularly visible using trichrome/elastic stains. Yet, in all cases, internal elastic lamina calcification was the dominant histologic feature. In this respect, our findings are very different from those in Buerger's disease, idiopathic infantile arterial calcification, diffuse arterial calcified elastopathy, and pseudoxanthoma elasticum, where calcification of the internal elastic lamina is not the dominant feature.

In most cases, we observed internal elastic lamina calcification in multiple sections along the length of the coronary vasculature. In HIV-positive patients with this finding, $34 \%$ of the vessel segments exhibited internal elastic lamina calcification. In affected HIV-negative patients, $32 \%$ of the vessel sections had calcification of the internal elastic lamina. The left main coronary artery was involved in only one patient. When we observed calcification, we frequently noted prominence and eosinophilia of the adjacent internal elastic lamina on H\&E-stained sections. Conversely, when we noticed prominence of the internal elastic lamina but not calcification, we often found internal elastic lamina calcification in other coronary sections from the same patient. Von Kossa and Alizarin red stains confirmed that calcium was present along the internal elastic lamina where it was seen using $\mathrm{H} \& \mathrm{E}$, but adjacent prominent, eosinophilic areas of the internal elastic lamina did not stain for calcium. Thus, although internal elastic lamina prominence and hypereosinophilia may be early manifestations of calcification of this membrane, there is no direct evidence to confirm calcium deposition in these areas.

Many patients with calcification of the internal elastic lamina had very minimal atherosclerotic disease, whereas others had more extensive atherosclerosis and intimal calcification. HIV-positive patients with internal elastic lamina calcification had significantly less average coronary artery stenosis due to atherosclerosis than HIV-positive patients without internal elastic lamina calcification (21 and $37 \%$ luminal occlusion, respectively; $P=0.02$ ). Yet, for HIV-negative patients with and without calcification of the internal elastic lamina, this trend was reversed (38 and $26 \%$ luminal occlusion, respectively; $P=0.22$ ). In all cases, internal elastic lamina 

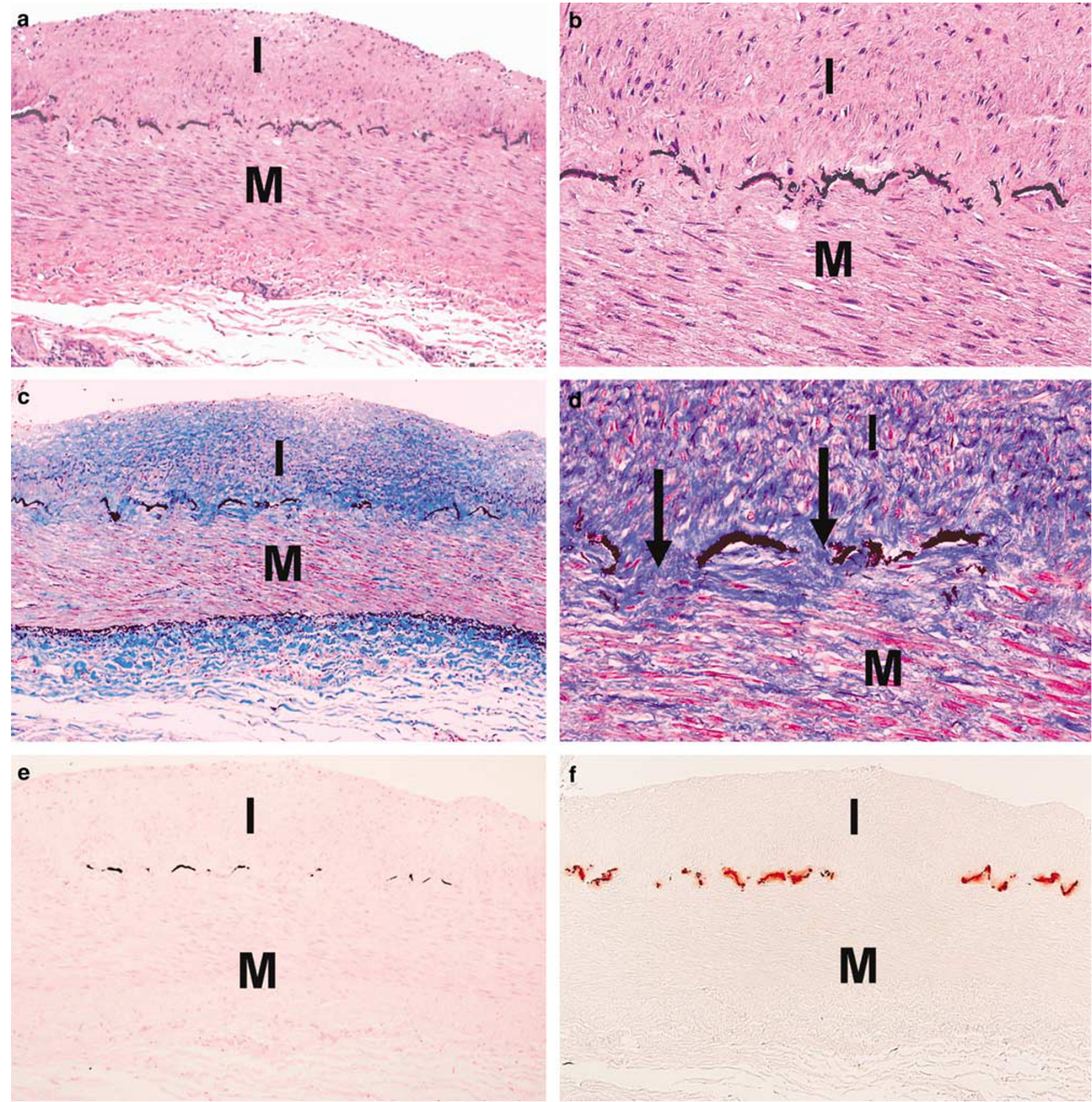

Figure 1 A 44-year-old woman with AIDS (Table 1). Example of calcification of the internal elastic lamina in a coronary artery with fibromuscular intimal hyperplasia: (a, b) H\&E stain demonstrating linear basophilic staining between intima (I) and media (M) ((a) $\times 40$, (b) $\times 100)$; (c, d) trichrome/elastic tissue stain confirming that the linear lesion is at the internal elastic lamina, which shows breaks associated with adjacent medial fibrosis (arrows) $((\mathbf{c}) \times 40$, (d) $\times 100)$; (e) von Kossa stain; and (f) Alizarin red stain confirming the presence of calcium $((\mathbf{a}, \mathbf{f}) \times 40)$.

calcification appeared to be completely distinct and histologically unrelated to intimal atherosclerosis and calcification.

\section{Systemic Histology}

Examination of general autopsy slides for these patients revealed arterial internal elastic lamina calcification in the mediastinal lymph nodes of six patients, in the thyroid glands of three patients, in the adrenal glands of two patients, and in the breast and skin of one patient each. The calcification was morphologically identical to that observed in the coronary arteries, as it was limited primarily to the internal elastic lamina but occasionally extended to adjacent intimal and medial tissues. Other systemic tissues showed evidence of diagnosed clinical 
1024
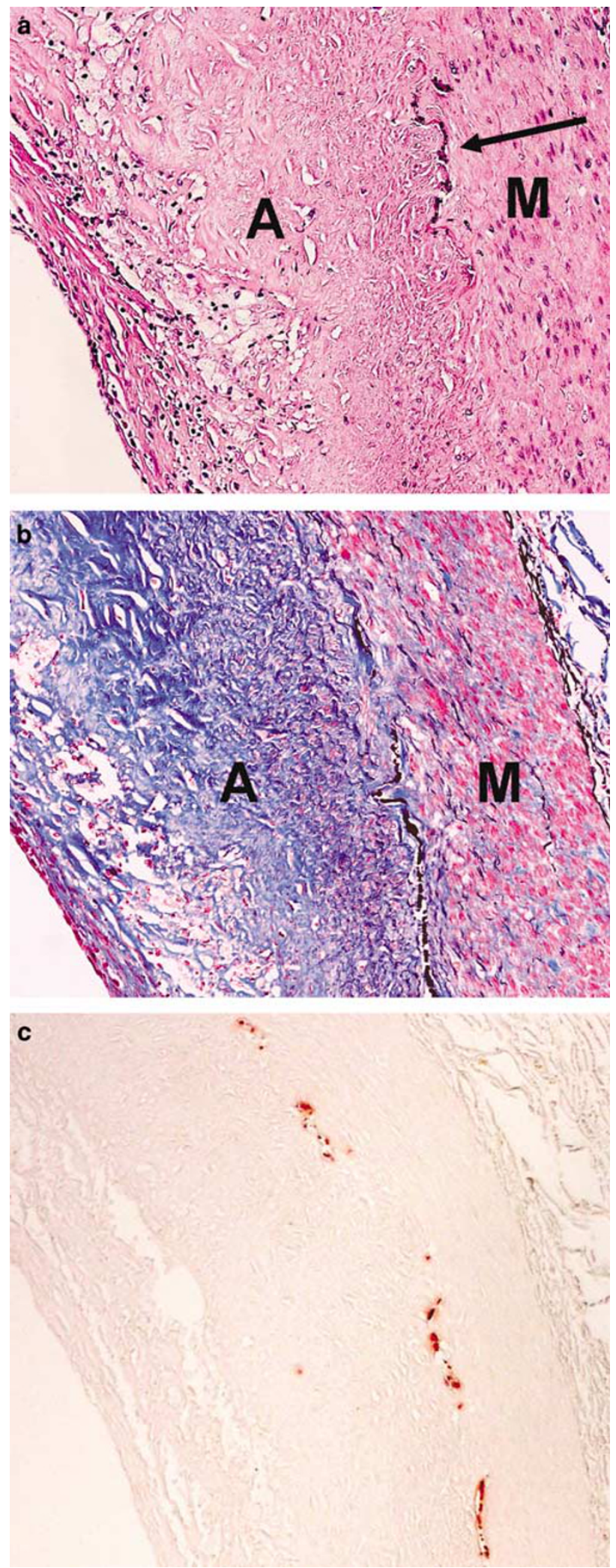

Figure 2 A 46-year-old man with AIDS (Table 1). Internal elastic lamina calcification in the region of atherosclerotic plaque in coronary artery: (a) H\&E stain showing basophilic staining (arrow) between media (M) and intimal atherosclerotic plaque (A); (b) trichrome/elastic tissue stain showing breaks in the region of calcification, and (c) Alizarin red stain confirming the presence of calcium (all $\times 40$ ). illnesses and cause of death. We noted minimal renal pathology in some cases but found no histologic evidence of chronic renal dysfunction.

\section{Discussion}

In this report, we describe an unrecognized, or at least not generally appreciated or reported, third form of coronary arterial calcification, namely, calcification limited primarily to the internal elastic lamina. Our findings suggest that internal elastic lamina calcification in the coronary arteries is separate from intimal calcification in atherosclerotic plaques and medial calcification described by Mönckeberg. Calcification begins on the internal elastic lamina and is most often limited to it. Subtle damage and disruption of the internal elastic lamina with associated intimal and medial fibrosis frequently accompany this calcification, suggesting that it is not a histologic artifact. Thus, internal elastic lamina calcification of the coronaries appears to be a distinct pathologic process of unknown cause and significance. Although not previously reported, it was rather common in the populations we studied.

Although coronary calcification limited to the internal elastic lamina has not been described before, Mönckeberg's sclerosis of the coronary arteries is a rare finding that has been reported previously in four cases. ${ }^{15-17}$ One of these cases, reported by Qiao et al, ${ }^{16}$ appears to have featured calcification of the internal elastic lamina as well as of the media. Our translations of Mönckeberg's original paper indicate that the medial calcification he described specifically spares the internal elastic lamina. Several subsequent authors agree., ${ }^{4,11,17}$ However, others maintain that Mönckeberg's sclerosis does involve the internal elastic lamina. Our recent study (Archives of Pathology and Laboratory Medicine, in press) found that Mönckeberg's sclerosis involved both the media and internal elastic lamina with calcification in all 14 of the arterial specimens we reviewed. In this study, however, we specifically noted no such cases of more extensive, Mönckebergtype medial calcification together with calcification of the internal elastic lamina. Thus, although we speculate that internal elastic lamina calcification may be a very early manifestation of Mönckeberg's medial sclerosis, we have no direct evidence showing a continuum between these processes.

Although the cases reported here lack the extensive intimal and medial damage associated with Buerger's disease, idiopathic infantile arterial calcification, diffuse arterial calcified elastopathy, and pseudoxanthoma elasticum, they are histologically similar to internal elastic lamina calcification observed in the orbital and temporal arteries. Of 105 temporal artery segments from patients older than 50, Lie et $a l^{18}$ observed internal elastic lamina calcification in $21 \%$. Similarly, Nordborg et $a l^{11}$ found such calcification in $39 \%$ of the 61 temporal 

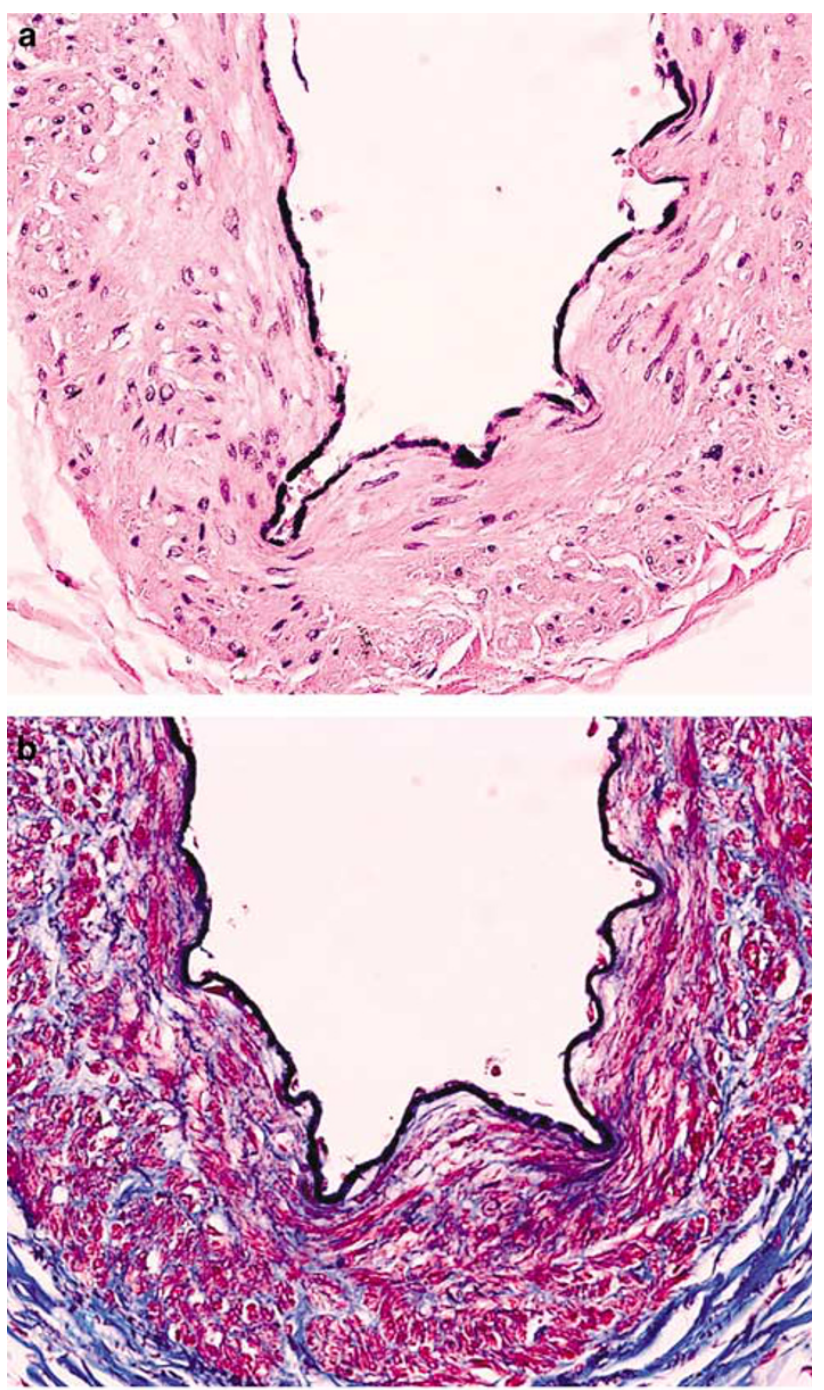

c

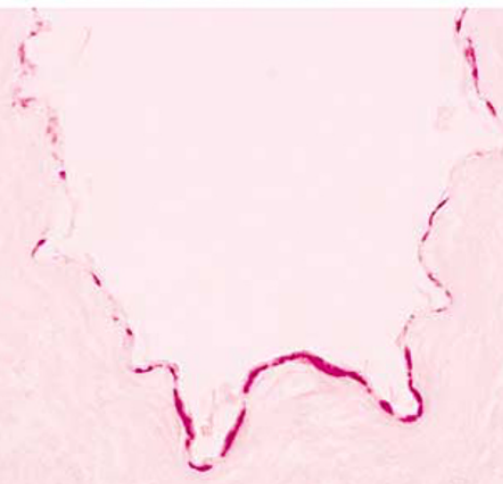

Figure 3 A 39-year-old man with AIDS (Table 1). (a) H\&E stain of coronary artery with no intimal thickening showing diffuse linear basophilic staining of internal elastic lamina; (b) trichrome/elastic tissue stain confirming that staining is of the internal elastic lamina, which is not fragmented, and (c) Alizarin red stain confirming the presence of calcium (all $\times 100)$. artery segments they studied (all patients older than 50). In both studies, this calcification was almost always limited to the internal elastic lamina, with occasional extension into the media. Disruption and fragmentation of the internal elastic lamina were frequent findings, ${ }^{18}$ and the calcifications bore no relationship to atherosclerotic disease. ${ }^{11}$ Internal elastic lamina calcification has also been reported in the orbital arteries of older patients (age $\geq 74$ ), where calcification was found to originate on the internal elastic lamina and enlarge symmetrically into the intima and media with frequent splitting, reduplication, and disruption of the internal elastic lamina. ${ }^{10}$ In all three studies, internal elastic lamina calcification was considered distinct from Mönckeberg's sclerosis. Similar to our observation, it was strongly associated with increasing age $(P=0.0006) .{ }^{11}$ In Lie's study, no patient under 50 years of age had temporal artery internal elastic lamina calcification. ${ }^{18}$

Thus, just as old age is a risk factor for intimal and medial calcification, the same seems to be true for calcification of the internal elastic lamina as reported in orbital, temporal, and now, coronary arteries. Because fragmentation and disruption of the internal elastic lamina also increase with age, ${ }^{18}$ and because they occur together with internal elastic lamina calcification, it is possible that there is a causal relationship between internal elastic lamina injury, disruption, and calcification, or vice versa. Internal elastic lamina injury in the absence of calcification has been linked to hypertension in old age $^{19}$ and has been implicated in the initiation of intimal thickening in human arteries. ${ }^{20,21}$

Yet, recent research has recast vascular calcification from a mere passive consequence of aging to a tightly regulated, active process featuring a host of factors. Normally, a balance exists between promoters and inhibitors of calcification, but in chronic renal dysfunction, diabetes mellitus, atherosclerosis, and osteoporosis, as well as aging, a dysregulation of calcification can occur. ${ }^{22}$ Each of these metabolic abnormalities is well documented in HIV-positive patients and may be due to HIV infection or to treatment with drugs such as protease inhibitors as part of highly active antiretroviral therapy (HAART). ${ }^{23-25}$

In a recent meta-analysis, $15 \%$ of HIV-infected patients had osteoporosis, for a pooled odds ratio of 3.7 compared to HIV-negative controls. ${ }^{26}$ In a separate study, vitamin D insufficiency $(81 \%)$ and secondary hyperparathyroidism $(26 \%)$ were other frequent findings among HIV patients treated with HAART for more than 5 years. ${ }^{25}$ Osteoporosis, hyperparathyroidism, elevated calcium phosphate product, chronic renal failure, and diabetes mellitus have all been associated with medial as well as intimal calcification. ${ }^{2,22,27,28}$ Although we have little evidence of patients in this study suffering from these conditions, many were HIV-infected and heavily exposed to HAART. It is possible that untested, subclinical, or unknown metabolic 

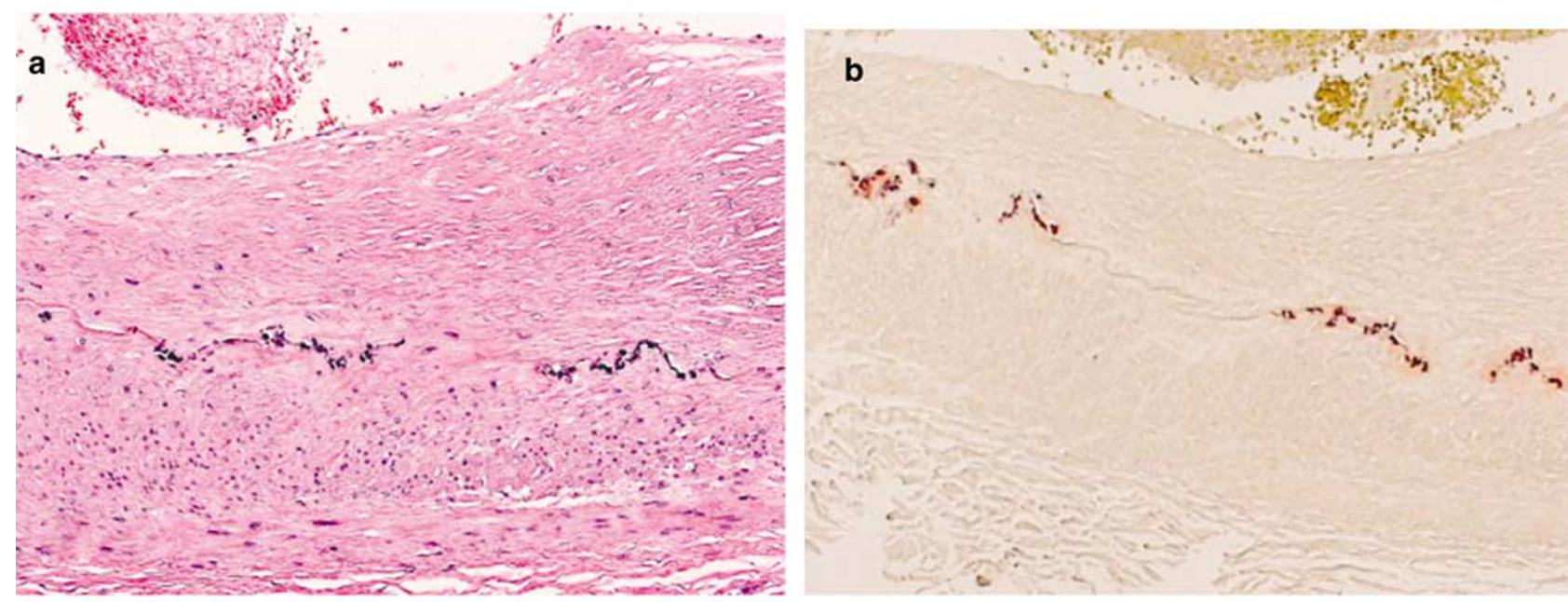

C
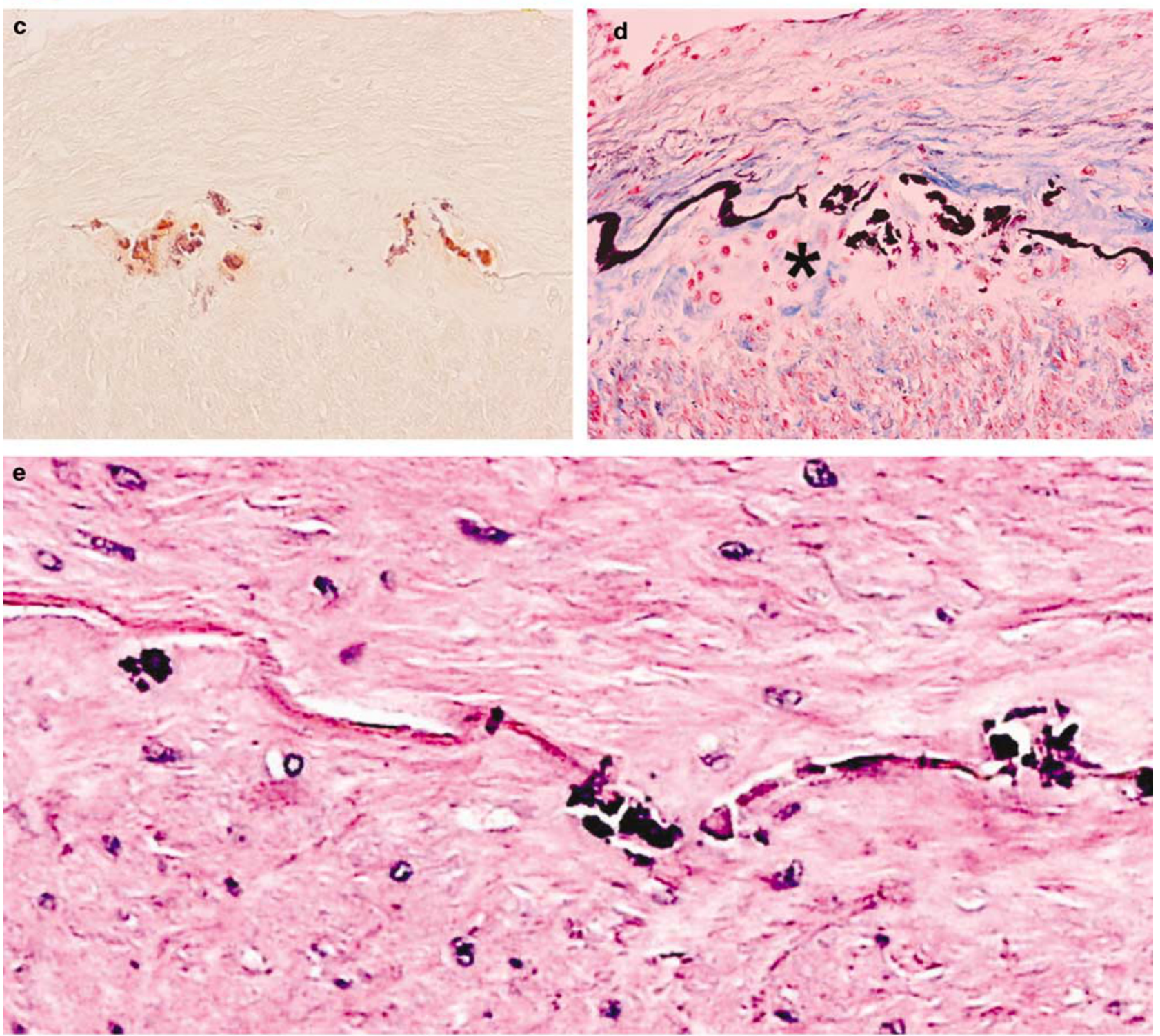

Figure 4 A 69-year-old HIV-negative woman (Table 1). (a) H\&E stain of coronary artery with fibrous plaque with linear basophilic staining in the region of the internal elastic lamina $(\times 40)$; (b, c) Alizarin red stain confirming the presence of calcium $((\mathbf{b}) \times 40$, $(\mathbf{c})$ $\times 200$ ): (d) trichrome/elastic tissue stain showing destruction of the internal elastic lamina with fibrosis (asterisk) of the underlying media in the region of the calcification $(\times 200)$; and (e) close-up of artery shown in (a) showing 'beads' of calcification with prominent, eosinophilic internal elastic lamina, which, unlike the basophilic regions, was negative by calcium stains $(\mathrm{H} \& \mathrm{E}, \times 400)$. 
disorders among the HIV-positive patients made them susceptible to damage and/or calcification of the internal elastic lamina at a younger age than HIV-negative controls. It is also possible the many medications to which these patients were exposed may have contributed to this finding.

The clinical significance of vascular calcification is not well defined, and calcification of the internal elastic lamina is no exception. Some argue that calcification of an intimal plaque predisposes it to rupture; others believe that calcification increases plaque stability. ${ }^{22}$ For many years, Mönckeberg's sclerosis was considered a completely benign condition; ${ }^{17,29}$ now it is thought to lead to increased pulse pressure, left ventricular hypertrophy, peripheral vascular disease, and altered coronary perfusion. ${ }^{3,28,30}$ Increasing amounts of calcification detected by computed tomography (CT) predict the likelihood of future coronary events. ${ }^{31}$ Yet, CT lacks the ability to distinguish between intimal and medial calcification. ${ }^{32}$ It is not known whether internal elastic lamina calcification leads to arterial stiffening and increased pulse pressure like medial calcification or whether its presence predicts clinically significant disease. It is also not known whether CT or other imaging techniques can detect internal elastic lamina calcification or distinguish it from other types of calcification. Thus, its presence could complicate the interpretation of screening methods to estimate the severity of coronary artery disease and the risk of cardiac events. As imaging techniques become more advanced and widespread, it may become possible to diagnose this type of calcification in living patients and determine what, if any, clinical significance it may have.

Potential limitations include the select group of patients with advanced illnesses examined. Although not all patients with internal elastic lamina calcification suffered from chronic diseases, this group is not representative of the population at large. In addition, because this was an autopsy study, our ability to collect clinical information was limited to those records available at the time of death. General autopsies, although complete, did not sample arteries of the viscera and extremities systematically, so our review of systemic arteries was limited.

\section{Acknowledgements}

We thank Dr Elyse J Singer, and David Jones of the National Neurological AIDS Bank for granting and facilitating access to tissue samples and clinical histories of patients enrolled in their study. We also thank Longsheng Hong for her histology laboratory expertise. This project was made possible by the generous funding from The National Neurological AIDS Bank (EJS), The Piansky Family Trust (MCF), and NIH K24 AI56933 (JSC).

\section{Disclosure/conflicts of interest}

None.

\section{References}

1 Simpson CL, Lindley S, Eisenberg C, et al. Toward cell therapy for vascular calcification: osteoclast-mediated demineralization of calcified elastin. Cardiovasc Pathol 2007;16:29-37.

2 Chen NX, Moe SM. Uremic vascular calcification. J Investig Med 2006;54:380-384.

3 Floege J, Ketteler M. Vascular calcification in patients with end-stage renal disease. Nephrol Dial Transplant 2004;19(Suppl 5):V59-V66.

4 Mönckeberg JG. Ueber die reine Mediaverkalkung der Extremitaetenarterien und ihr Verhalten zur Arteriosklerose. Virchows Arch Pathol Anat 1903;171:141-167.

5 Kim EJ, Cho BS, Lee TS, et al. Morphologic change of the internal elastic lamina in Buerger's disease. J Korean Med Sci 2000;15:44-48.

6 van der Sluis IM, Boot AM, Vernooij M, et al. Idiopathic infantile arterial calcification: clinical presentation, therapy and long-term follow-up. Eur J Pediatr 2006;165:590-593.

7 Inwald DP, Yen Ho S, Shepherd MN, et al. Idiopathic infantile arterial calcification presenting as fatal hypertensive cardiomyopathy. Arch Dis Child 2006;91:928.

8 Gubler MC, Antignac C, Broyer M, et al. Diffuse arterial calcified elastopathy-a new cause of renovascular hypertension in children. Int J Pediatr Nephrol 1985;6: 47-54.

9 Laube S, Moss C. Pseudoxanthoma elasticum. Arch Dis Child 2005;90:754-756.

10 Buchi ER, Schiller P, Felice M, et al. Common histopathological changes in aged human orbital arteries. Int Ophthalmol 1993;17:37-42.

11 Nordborg C, Nordborg E, Petursdottir V, et al. Calcification of the internal elastic membrane in temporal arteries: its relation to age and gender. Clin Exp Rheumatol 2001;19:565-568.

12 Nordborg C, Nordborg E, Petursdottir V. The pathogenesis of giant cell arteritis: morphological aspects. Clin Exp Rheumatol 2000;18:S18-S21.

13 Schwarz U, Buzello M, Ritz E, et al. Morphology of coronary atherosclerotic lesions in patients with end-stage renal failure. Nephrol Dial Transplant 2000;15:218-223.

14 Weenig RH, Sewell LD, Davis MD, et al. Calciphylaxis: natural history, risk factor analysis, and outcome. J Am Acad Dermatol 2007;56:569-579.

15 Lanzer P. [Monckeberg media calcinosis]. Z Kardiol 1998;87:586-593.

16 Qiao JH, Doherty TM, Fishbein MC, et al. Calcification of the coronary arteries in the absence of atherosclerotic plaque. Mayo Clin Proc 2005;80:807-809.

17 Lachman AS, Spray TL, Kerwin DM, et al. Medial calcinosis of Monckeberg. A review of the problem and a description of a patient with involvement of peripheral, visceral and coronary arteries. Am J Med 1977;63:615-622.

18 Lie JT, Brown Jr AL, Carter ET. Spectrum of aging changes in temporal arteries. Its significance, in interpretation of biopsy of temporal artery. Arch Pathol 1970;90:278-285. 
19 Cook TA, Salmo NA, Yates PO. The elasticity of the internal lamina. J Pathol 1975;117:253-258.

20 Jones GT, Jiang F, McCormick SP, et al. Elastic lamina defects are an early feature of aortic lesions in the apolipoprotein E knockout mouse. J Vasc Res 2005;42:237-246.

21 Sims FH. The initiation of intimal thickening in human arteries. Pathology 2000;32:171-175.

22 Johnson RC, Leopold JA, Loscalzo J. Vascular calcification: pathobiological mechanisms and clinical implications. Circ Res 2006;99:1044-1059.

23 Hsue PY, Waters DD. What a cardiologist needs to know about patients with human immunodeficiency virus infection. Circulation 2005;112: 3947-3957.

24 Szczech LA, Gupta SK, Habash R, et al. The clinical epidemiology and course of the spectrum of renal diseases associated with HIV infection. Kidney Int 2004;66:1145-1152.

25 Seminari E, Castagna A, Soldarini A, et al. Osteoprotegerin and bone turnover markers in heavily pretreated HIV-infected patients. HIV Med 2005;6: $145-150$.
26 Brown TT, Qaqish RB. Antiretroviral therapy and the prevalence of osteopenia and osteoporosis: a meta-analytic review. Aids 2006;20:2165-2174.

27 Lanzer P. [Media calcinosis from the viewpoint of the cardiologist]. Z Kardiol 1998;87:928-938.

28 Dao HH, Essalihi R, Bouvet C, et al. Evolution and modulation of age-related medial elastocalcinosis: impact on large artery stiffness and isolated systolic hypertension. Cardiovasc Res 2005;66:307-317.

29 Silbert S, Lippmann HI. Moenckeberg's sclerosis. A clinical entity. J Mt Sinai Hosp, NY 1945;12-13:689-700.

30 Shanahan CM, Cary NR, Salisbury JR, et al. Medial localization of mineralization-regulating proteins in association with Monckeberg's sclerosis: evidence for smooth muscle cell-mediated vascular calcification. Circulation 1999;100:2168-2176.

31 Nicholls SJ, Tuzcu EM, Wolski K, et al. Coronary artery calcification and changes in atheroma burden in response to established medical therapies. J Am Coll Cardiol 2007;49:263-270.

32 London GM, Marchais SJ, Guerin AP, et al. Arteriosclerosis, vascular calcifications and cardiovascular disease in uremia. Curr Opin Nephrol Hypertens 2005;14:525-531. 